\title{
Trafik Yoğunluk Harita Görüntülerinin Görüntü İşleme Yöntemleriyle İşlenmesi
}

\author{
${ }^{1}$ G. Çiğdem Çavdaroğlu \\ ${ }^{1}$ Koç Sistem, İstanbul \\ cavdarkizi@gmail.com \\ Geliş Tarihi: 2017-02-03 Kabul Tarihi: 2017-06-30
}

\begin{abstract}
$\ddot{O} \mathbf{z}$
Bu çalışmada, “Akıllı Şehirler” konulu uluslararası bir Ar-Ge projesi olan INSIST projesi kapsamında geliştirilen, yaygın olarak kullanılan trafik yoğunluk haritası uygulamalarından elde edilen görüntüleri işleyerek yoğunluk verisi üreten bir yöntem sunulmaktadır. INSIST projesi, akıllı şehirlere yönelik olarak güvenlik - reklam - şehir aydınlatması uygulamalarını barındırmayı ve bu uygulamalara veri sağlamayı adreslemektedir. Akıllı Şehirler konusunun en önemli unsurlarından birisi olan akıllı ulaşım sistemlerinin kilit verilerinden birisi de trafik yoğunluk verileridir. Şehirde yaşayan ve trafikte aktif olarak var olan kişilerin akıllı yöntemler ile trafik hakkında bilgilendirilmesi, öncelikli araçlara hem en kısa hem de en uygun olan rotaların önerilmesi için trafik yoğunluk verileri çok önemli bir veri kaynağıdır. Şehrin çeşitli konumlarına farklı kamu kurumları tarafından yerleştirilen kameralar yardımıyla bu verinin elde edilmesi mümkündür, ancak bu hem maliyetli hem de kamera konum ve sayılarına bağımlı olması nedeniyle sınırlı bir yöntemdir. Bu çalışmada, bu yönteme bir alternatif olarak geliştirilen ve internet üzerinden trafik yoğunluk verilerini sunan uygulamalardan elde edilen görüntülerin işlenmesi ile trafik yoğunluk verilerini üreten bir yöntem sunulmuştur.
\end{abstract}

Anahtar kelimeler: Akıllı şehirler, akıllı ulaşım, trafik yoğunluğu

\section{Processing of Traffic Density Map Images Using Image Processing Techniques}

\author{
${ }^{1}$ G. Çiğdem Çavdaroğlu \\ ${ }^{1}$ Koç System, Istanbul \\ cavdarkizi@gmail.com \\ Received date: 2017-02-03 Accepted date: 2017-06-30
}

\begin{abstract}
This paper presents a method which is developed in an international R\&D project called INSIST on the subject "Smart Cities", to extract traffic density information from traffic density maps by implementing image processing techniques. INSIST project addresses hosting security - advertisement - lighting applications developed for smart cities and providing required data to this applications. Intelligent transport systems is a very important key feature of smart cities. One of the key data source of intelligent transport systems is traffic density data. Traffic density data is required for navigating active drivers in the traffic using smart methods and suggesting alternative routes to the emergency vehicles.Although this required data can be gathered from the video cameras located at various locations around the city, this method is very expensive and limited to the camera locations and count. This paper presents an alternative method in order to gather traffic density data. The presented method uses the screenshots of traffic density maps and processes them by image processing algorithms.
\end{abstract}

Keywords: Smart cities, intelligent transport, traffic density

\section{Giriş}

Günümüzde insan nüfusunun büyük bir çoğunluğu, şehirlerde yaşamaktadır ve şehirleşme gün geçtikçe artmaktadır. Şehirlerde bireyler kendi araçlarını kullanmakta ve her gün artan trafiğe giren araç sayısı

Sorumlu yazar: Koç Sistem, İstanbul, Türkiye, E mail: cavdarkizi@gmail.com 
ile trafik şehirler için önemli bir problem teşkil etmektedir. Mevcut ulaşım altyapısı ve yönetim yaklaşımları, birçok ülkede artık trafikle baş edememektedir. $\mathrm{Bu}$ da birçok insanın trafikte gereksiz yere zaman kaybetmesine, gereksiz yakıt tüketimine yol açmaktadır [1].

Dünya nüfusundaki hızlı artış ile birlikte önümüzdeki 20 yıllık zaman dilimi içerisinde şehirlerde yaşayan kişi sayısının 2.8 milyardan 5 milyara çıkması beklenmektedir. Şehirlerin bu durum için hazırlık yapması, mevcut altyapıların iyileştirmeleri, kaynaklarını verimli kullanarak yenilikçi, yönetilebilir ve entegre hizmetler sunmaları gerekmektedir. Uluslararası çok ortaklı bir Ar-Ge projesi olan INSIST projesinde, geleceğin akılı şehirlerine yönelik, entegre veri ve servis platformunun oluşturulması, çeşitli kullanım senaryoları doğrultusunda algoritma, servis ve uygulamaların geliştirilmesi hedeflenmektedir [2].

INSIST platformu, trafiğe ilişkin belli başlı önemli bilgileri çeşitli kaynaklardan toplayarak, farklı uygulamalar aracılığıyla kamu kurum ve kuruluşlarına ve son kullanıcılara sunmayı hedeflemektedir. Trafiğe ilişkin en önemli verilerden birisi de trafik yoğunluk verisidir. Proje kapsamında trafik yoğunluk verilerinin toplanması için 3 farklı yöntem üzerine odaklanılmıştır:

1. Kameralar aracılığıyla elde edilen görüntülerin işlenmesi ile

2. Sosyal medya kanallarından elde edilen yorumların işlenmesi ile

3. Trafik yoğunluk haritalarına ilişkin ekran görüntülerinin işlenmesi ile

3 farklı kaynaktan elde edilen veriler bir araya getirilerek hizalanabilecek ve en doğru verinin üretilmesi sağlanabilecektir. Bu çalışmada, trafik yoğunluk haritalarının ekran görüntülerinin grüntü işleme yöntemleri ile işlenmesi yoluyla trafik yoğunluk verisinin elde edilmesini sağlayan yöntem açıklanmaktadır. Sunulan yöntem, farklı trafik yoğunluk haritalarının eş zamanlı olarak izlenebilmesini ve görüntülerden otomatik yöntemlerle bilgi çıkarımı yapılabilmesini sağlayacaktır. Ayrıca harita görüntüleri içerisinden yol objelerinin görüntü işleme yöntemleri ile elde edilebilmesi, görüntü haline getirilmiş bir haritanın nasıl yeniden koordinatlı bir hale getirilebileceği hakkında fikir verecektir.

\subsection{Tekniğin Bilinen Durumu}

Trafik yoğunluk harita ekran görüntülerinden, yoğunluğa göre renklendirilmiş yol verilerinin elde edilmesine yönelik olarak literatürde bir çalışma yer almamakla birlikte, sunulan yönem, temel amacı açısından hava görüntülerinden yol verilerinin görüntü işleme yöntemleri ile elde edilmesine dayanan çalışmalara benzetilebilir.

Hava görüntülerinden, yol verilerinin elde edilmesine yönelik olarak gerçekleştirilmiş birçok çalışma, Bajcsy ve Tavakoli'nin çalışmasını başlangıç noktası olarak almaktadır [3]. Bu çalışma, görüntü içerisinde yer alan kenar ya da diğer temel bileşenlerin elde edilmesi, elde edilen bileşenlerin gruplanması ve sonuç yol ağının elde edilmesini sağlayan eleme tekniklerinin uygulanması aşamalarını içermektedir. Laptev ve arkadaşları tarafından geliştirilen yöntemde, yol ağı önce kabaca bulunur, ardından gerçek yol ağının elde edilmesi amacıyla şerit yılan (ribbon snake) modeli uygulanır [4]. Mena ve Malpica tarafından geliştirilen yöntemde, öncelikle segmentasyon yapılır, ardından iskelet çıkarımı uygulanmaktadır [5]. Bir diğer strateji de otomatik olarak elde edilen başlangıç noktalarından ya da bir uzman desteği ile işaretlenen başlangıç noktalarından başlamak suretiyle yolların izlenmesine dayanmaktadır [6, 7]. Hava fotoğraflarından yol verilerinin elde edilmesi konusunda temel olarak kabul edilen bir diğer çalışma da Boggess tarafından sunulmuştur [8]. Boggess'in çalışmasında, hava fotoğrafi içerisinde yer alan $5 \times 5$ boyutundaki piksel kümeleri, bir yapay sinir ağına sokularak yol / yol değil olarak işaretlenmektedir. Izleyen yıllarda, yapay sinir ağının kullanımıyla yol verisi elde edilen başka yöntemler de geliştirilmiştir [9, 10]. 9x9'luk piksel kümeleri üzerinde çalışan bu yöntemler, Boggess'in çalışmasında elde edilen sonucu geliştirmemiştir ve çok küçük boyutta bir veri seti üzerinde test edilmiştir. Dollar ve arkadaşları tarafından geliştirilen yöntemde, nesnelerin sınırlarının öğrenilmesine ilişkin genel bir mantık kullanılmıştır [11]. Bu yöntemde, her pikseli kapsayan büyük bir alanda, önceden tanımlanmış onbinlerce detayın araması yapılmaktadır. Tahminleme noktasında olasılık ağacı kullanılmıştır. Ancak çalışma üç örnek resim üzerinde çalıştırılmış ve prototip düzeyde kalmıştır. Yol yakalama algoritmalarında, daha iyi sonuçlar elde edilmesi için, genellikle, yol ağının yapısı hakkında bir ön bilgi edinilmesini sağlayan aktif kontür modelleri kullanılmaktadır [4, 12].

\section{Metot}

\subsection{Trafik Yoğunluk Haritalarının Görüntü İsleme Yöntemleri ile İslenmesi}

$\mathrm{Bu}$ çalışmada pilot bölge olarak İstanbul şehri seçilmiştir. Proje kapsamında geliştirilen platformun temeline yerleştirilmesi gereken harita verisinin (bu çalışma için İstanbul'a ilişkin coğrafi veri) üretilmesi için açık kaynak kodlu harita uygulaması olan OpenStreetMap [13] kullanılmıştır. Trafik yoğunluk 
haritaları, trafik yoğunluklarını önceden belirlenmiş bir renk skalası kullanarak görselleştirirler. Yaygın olarak kullanılan ve İnternet üzerinden sunulan bu uygulamalara örnek olarak Yandex, Google Maps, İBB Trafik verilebilir. Trafik yoğunluk harita uygulamalarından, belirli bir bölgeye özel olarak, ekran görüntüsü alınarak belirli frekanslarda trafik yoğunluk haritası görüntülerinin elde edilmesi mümkündür. $\mathrm{Bu}$ çalışmada Google Maps uygulamasının trafik yoğunluk haritaları baz alınmıştır. Google Maps yoğunluk haritası üzerinde yer alan renkler, yol üzerinde trafik akışına işaret etmektedir. Anlamları ise şu şekildedir:

- Yeşil: Akıcı

- Turuncu: Orta miktarda trafik

- Kırmızı: Yoğun (Kırmızı tonu koyulaştıkça, akış daha da yavaşlamaktadır.)

Görüntü işleme yöntemleri kullanılarak, Google Maps'a ilişkin renk skalası ve uygulama özelinde takip edilen kurallar gözetilerek yoğunluk resimlerinden renk ve yol bilgilerinin çekilmesi ve anlamlandırılması kurgulanmıştır. Görüntü içerisinden yakalanan yol verilerinin harita üzerinde konumlandırılabilmesi için (gerçekte hangi yola ait olduğunu bulabilmek için) resim verisi ile harita arasında bir ilişki kurulması gerekli olmuştur. Bu yöntem ile yoğunluk verisinin elde edilebilmesi için yapılması gerekli olan işlemler şöyle listelenebilir:

- Resim verisinin harita verisi ile eşleştirilmesi

- Resim verisinin görüntü işleme yöntemleri ile işlenmesi sonucunda yoğunluk renklerinin belirlenmesi

- Resim verisinin görüntü işleme yöntemleri ile işlenmesi sonucunda yoğunluk renklerine ilişkin yol verilerinin belirlenmesi
- Resim verisi üzerinden elde edilen yol verilerinin, harita üzerindeki karşılıklarının bulunmas1

\subsection{Görüntünün Haritaya Çevrilmesi}

Bu adım, "resmin sayısallaştırılması" olarak da isimlendirilebilir. Sayısallaştırma işlemi, fotogrametrik yöntemlerle elde edilen raster verilerin $\mathrm{CAD}$ uygulamaları içerisinde görsel olarak sunulması, bu görsel üzerinden $\mathrm{CAD}$ araçları ile coğrafi bileşenlerin bir operatör tarafından sayısal ortama çizilmesi ile yapılan bir işlemdir. Resim sayısallaştırmanın otomatik hale getirilebilmesi için görüntü içerisinde kalan coğrafi verilerin konum bilgileri ile eşleştirilmesi gerekmektedir. Görüntünün dört köşesine (üst sol, üst sağ, alt sol , alt sağ) ilişkin konum bilgilerinin elde edilmesi, görüntü genişlik - uzunluk bilgilerinin resim meta verilerinden alınması ile piksel bazında her nokta için karşılık gelen konum verilerinin hesaplanması mümkündür. Genişlik değerine karşılık gelen gerçek dünya metre verisi ile görüntünün genişlik piksel uzunluk değerinin kullanımıyla, her bir piksel için piksel genişliği bazındaki gerçek dünya değeri metre ve kilometre cinsinden hesaplanmıştır. Aynı şekilde uzunluk değerleri de kullanılarak her bir piksel için piksel uzunluğu bazındaki gerçek dünya değeri metre ve kilometre cinsinden hesaplanmıştır. $\mathrm{Bu}$ değerlerin kullanımıyla elde edilen formülasyon kullanılarak, her bir piksel için o piksele karşılık gelen gerçek dünya koordinat verileri hesaplanmıştır. Formülasyonların oluşturulması aşamasında, iki gerçek dünya koordinatı arasındaki gerçek mesafenin hesaplanması için Haversine formülü [14] kullanılmıştır.

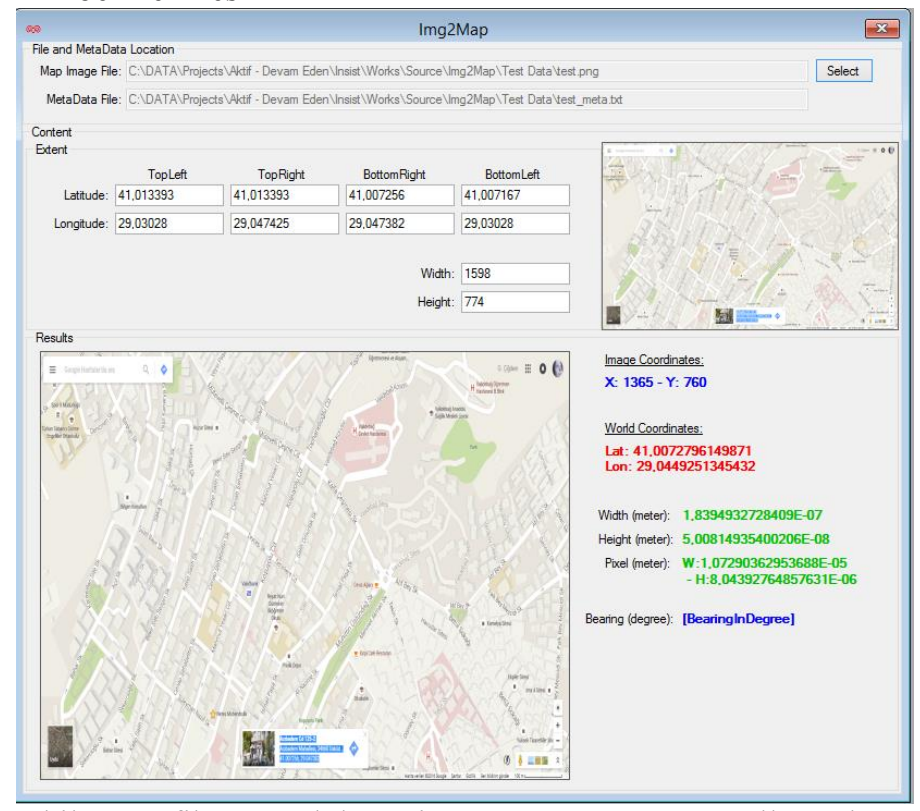

Şekil 1. Trafik Yoğunluk Harita Görüntüsünün Sayısallaştırılması 
İki gerçek dünya koordinatı arasındaki gerçek mesafe değerini hesaplamak için kullanılan Haversine formülü denklem 1'de görülmektedir.

$$
\begin{gathered}
a=\sin ^{2}(\Delta \varphi / 2)+\cos \varphi_{1} \cdot \cos \varphi_{2} \cdot \sin ^{2}\left(\frac{\Delta \lambda}{2}\right) \\
c=2 \cdot \operatorname{atan}^{2}(\sqrt{a}, \sqrt{(1-a)}) \\
d=R . c
\end{gathered}
$$

Denklem 1. Haversine Formülü: $\varphi$ enlem, $\lambda$ boylam, $\mathrm{R}$ dünyanın yarıçapı (ortlama $6,371 \mathrm{~km}$ )

\subsection{Görüntü İçerisinde Yer Alan Yoğunluk Renkli Yolların EIde Edilmesi}

Trafik yoğunluk harita görüntüsü içerisinde yoğunluğu belirtilen yolların görüntü koordinatlarının elde edilmesi için Google Maps tarafından kullanılan renk skalası dikkate alınmıştır. Google Maps trafik yoğunluk haritasında yer alan yollar yeşil, turuncu ve kırmızı renkler ile gösterilmektedir. Görüntü içerisinde bu renklere ilişkin birbirini takip eden ve süreklilik gösteren bileşenler Hough dönüşümü [15] kullanılarak yakalanmıştır. Şekil 2'de örnek bir Google Maps trafik yoğunluk haritası ve yoğunluğuna göre renklendirilmiş yollar görülmektedir.

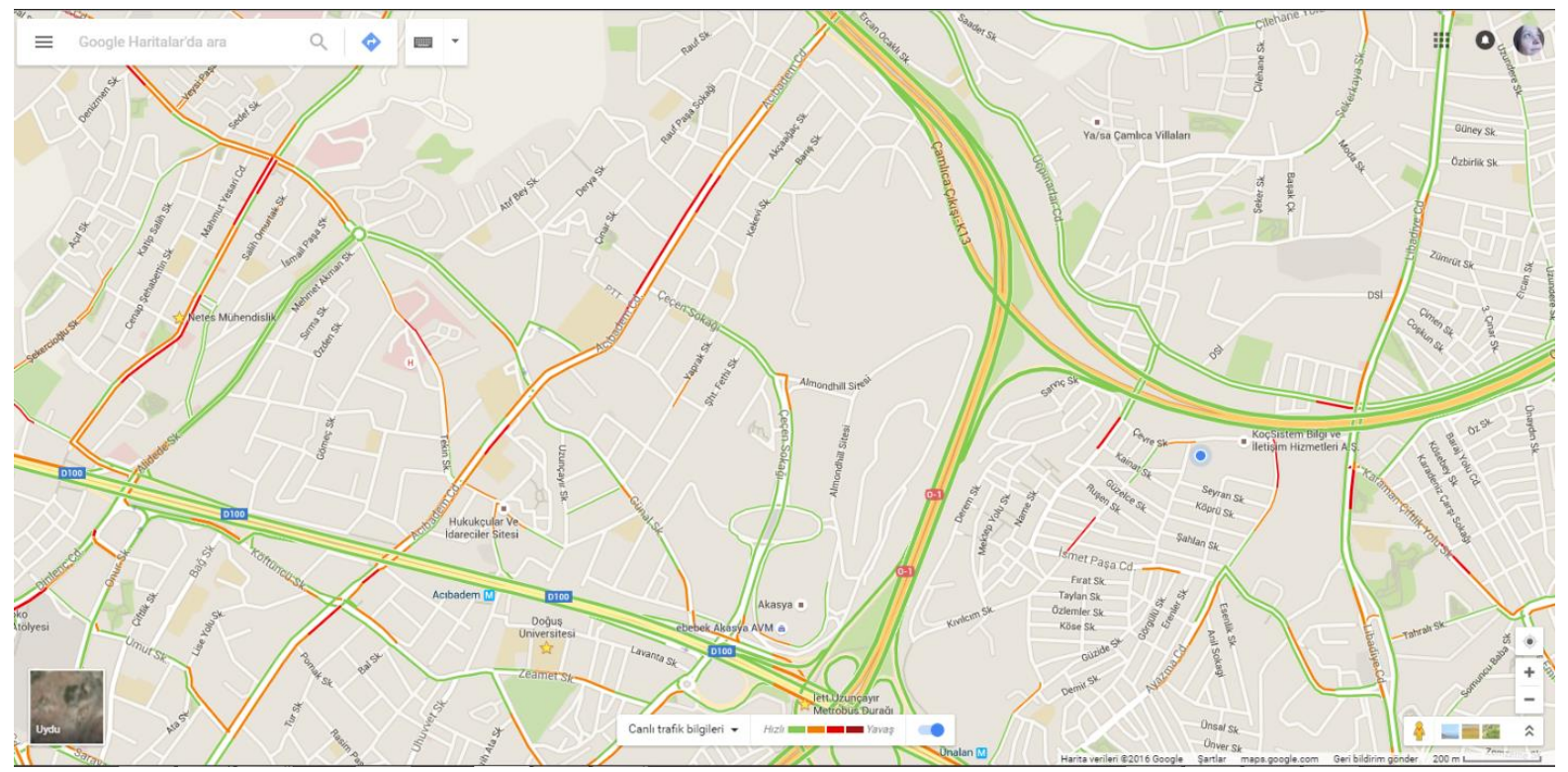

Şekil 2. Trafik Yoğunluk Haritası ve Yoğunluğuna Göre Renklendirilmiş Yollar

$\mathrm{Bu}$ veri üzerinde yapılan işlemler sonucu elde edilen sonuçlar şekil 4'te gösterilmiştir. Google Maps'te kırmızı ile gösterilen yoğun yollar resimde siyah ile, turuncu ile gösterilen orta yoğunlunlukta yollar resimde mavi ile, yeşil ile gösterilen akıcı yollar ise resimde sarı ile gösterilmiștir. Şekil 3'te sol tarafta pilot bölgenin Google Maps görüntüsü, sağ tarafta geliştirilen yöntemin uygulanması sonucu elde edilen yolların görüntüsü görülmektedir.

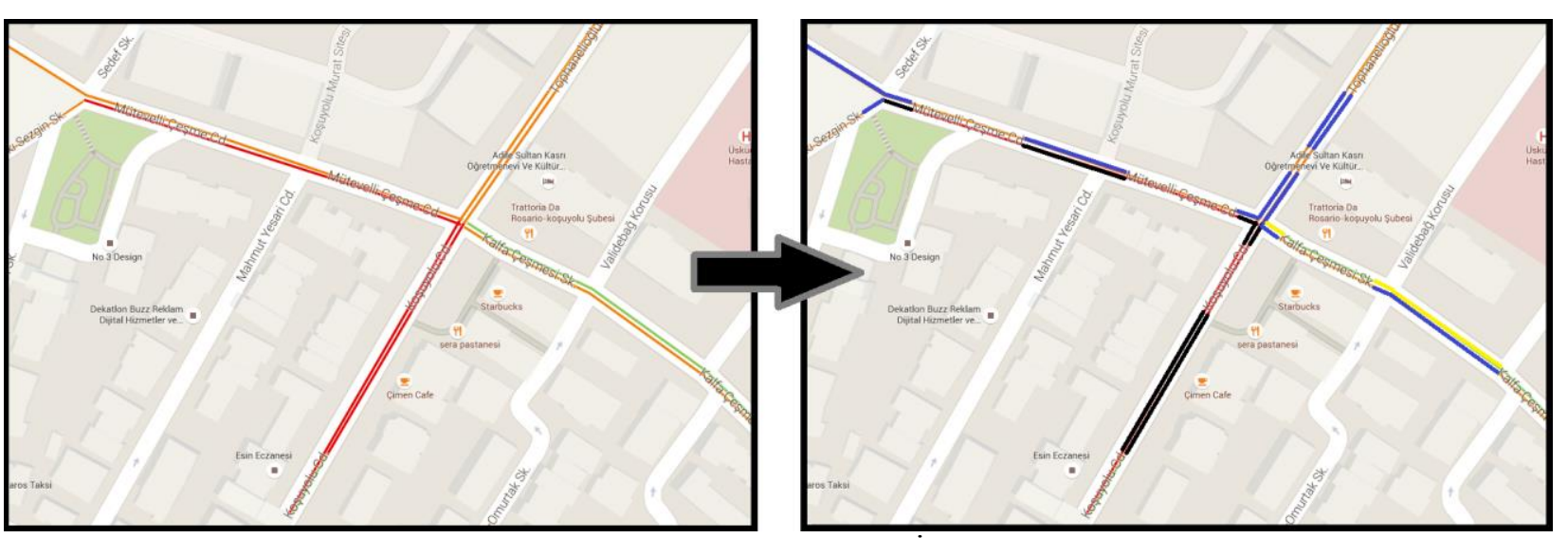

Şekil 3. Pilot Bölge - Google Maps Görüntüsü ve İşlenme Sonrası Görüntü 


\subsection{B Yol Verisinin Harita Koordinatlı Yol Verisi İle İlişkilendirilmesi}

Renk skalası baz alınarak harita görüntüsü içerisinde bulunan yol verileri, görüntü koordinatları ile birlikte bulunmaktadır. Elde edilen veri, görüntü içerisinde yer alan çizgilerin görüntü koordinatları bilinen noktaların birleşmesi ile elde edilen çizgi ve çoklu çizgilerdir. Harita görüntüsünün sayısallaştırılması sırasında, her bir piksel için gerçek dünya uzunluğu ve yüksekliği verileri elde edilmiştir. $\mathrm{Bu}$ değerler kullanılarak elde edilen dönüşüm formülasyonu kullanılarak bu çizgileri oluşturan noktaların görüntü koordinatları gerçek dünya koordinatlarına dönüştürülmüş ve elde edilen yolların gerçek dünya koordinatlarından oluşan bir sonuç seti elde edilmiştir.

\subsection{Bulgular}

Renk skalası bazında geliştirilen algoritma, skalada yer alan renklerin ayırt edici nitelikte olmalarına bağlı olarak başarılı sonuç üretmiştir. Harita uygun ölçekte gösterildiğinde elde edilen ekran görüntülerinde yer alan yoğunluk renklerinin ayrımında bir hata gözlenmemiştir. Ancak yol adı ve diğer coğrafi detaylara ilişkin yazı bilgilerinin yer aldığ 1 sembolizasyon nesneleri, algoritmanın çalışmasında problem oluşturmuştur. Renk skalasına baz almasının yanı sıra, algoritmanın dikkat ettiği bir diğer kriter de, skalaya uygun olarak bulunan bölgenin devam eder nitelikte bir geometrik nesneye ilişkin olmasıdır. Bahsi geçen sembolizasyon nesnelerinin, bulunan geometrik nesnelerin sürekliliğini bozması nedeniyle algoritmada problemler yaşanmıştır. Şekil 4'te hataya yol açan bölgeler dikdörtgen içerisine alınarak belirtilmiştir.

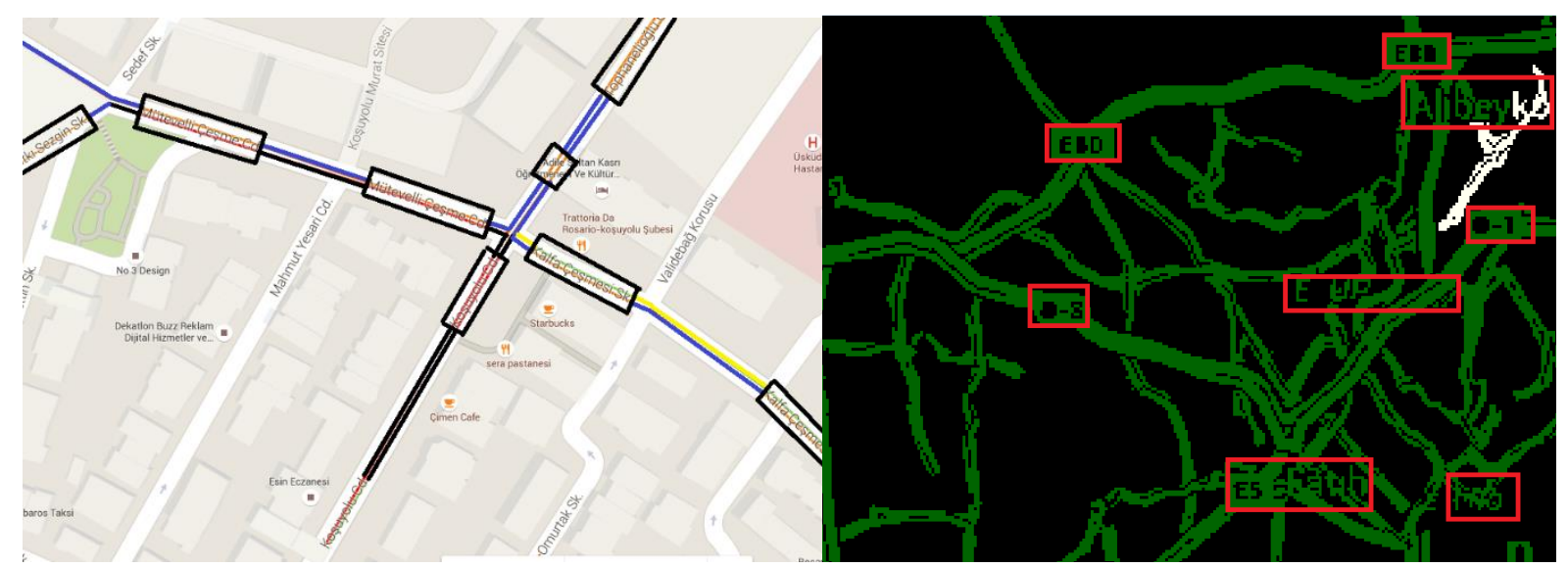

Şekil 4. Hatalar

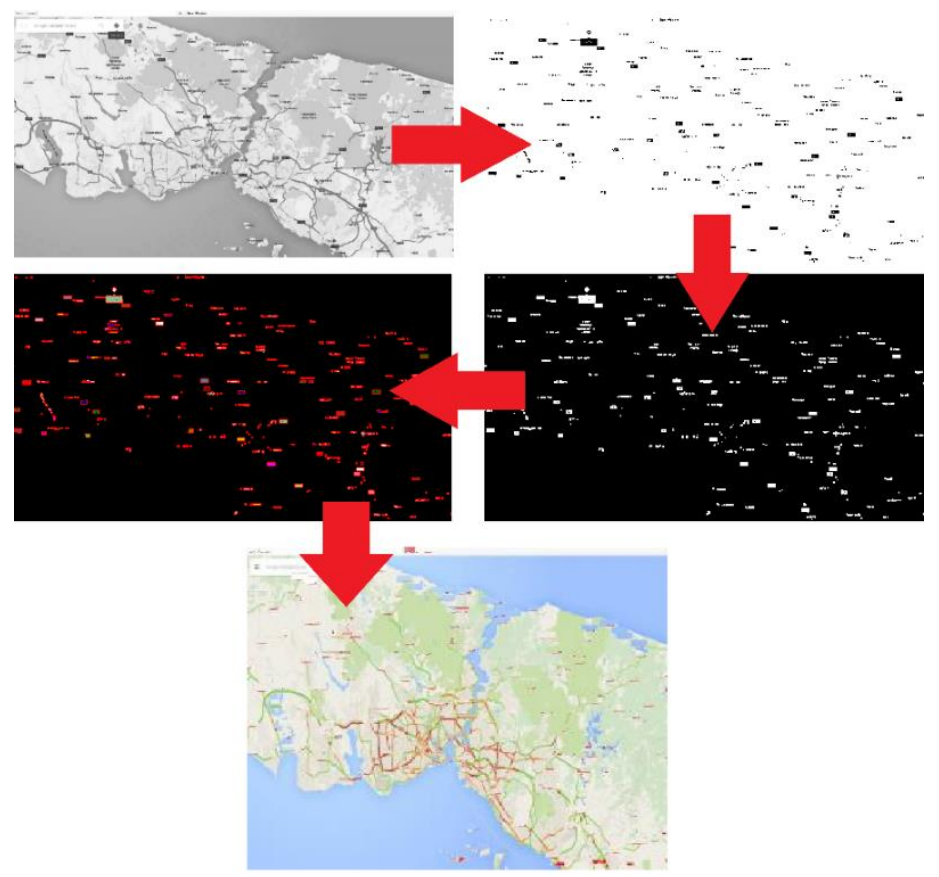

Şekil 5. Görüntü Ön İşleme: Yazı Sembolizasyonlarının Silinmesi 
Probleme neden olan sembolizasyon nesnelerinin bir ön işleme ile görüntüden silinmesi ve diğer işlemlere bu adımdan sonra devam edilmesi ile işlemin doğruluğu artırılmıştır. Yol verileri bulunmasından önce, harita üzerinde yer alan yazı bileșenleri
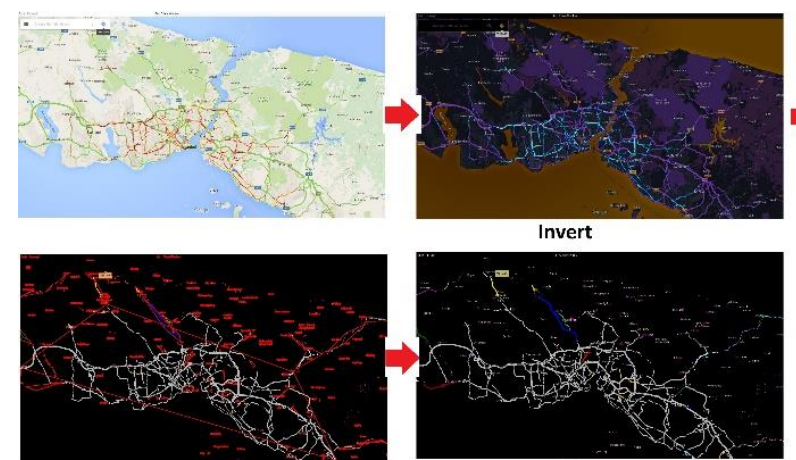

Connected Components

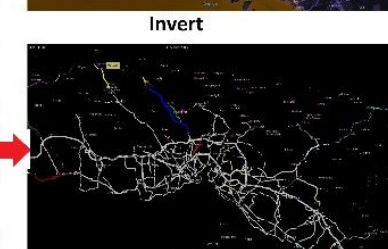

Blobs kaldırılarak yol bileşenleri sürekli bir şekilde bulunabilmiştir. Şekil 5'te bu işlem adımları ve elde edilen sonuç görülmektedir. Ön işleme sonrasında yol nesnelerinin bulunmasına ilişkin sonuçlar şekil 6'da görülmektedir:

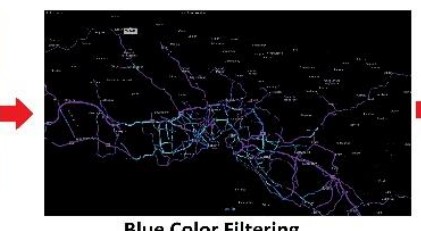

Blue Color Filtering
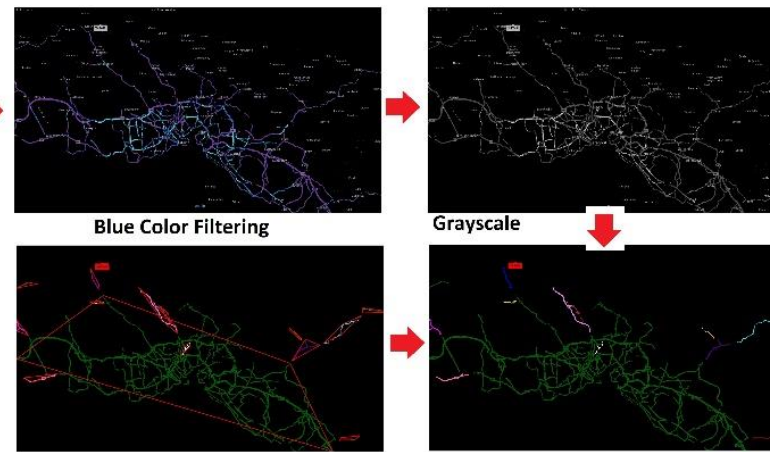

Connected Components (Filtered)

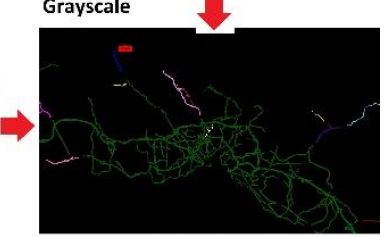

Blobs (Filtered)

Şekil 6. Ön İşleme Sonrası Yol Nesnelerinin Elde Edilmesi Sonuç Akışı

Yönteme ilişkin akış diyagramı Şekil 7'de verilmiştir:

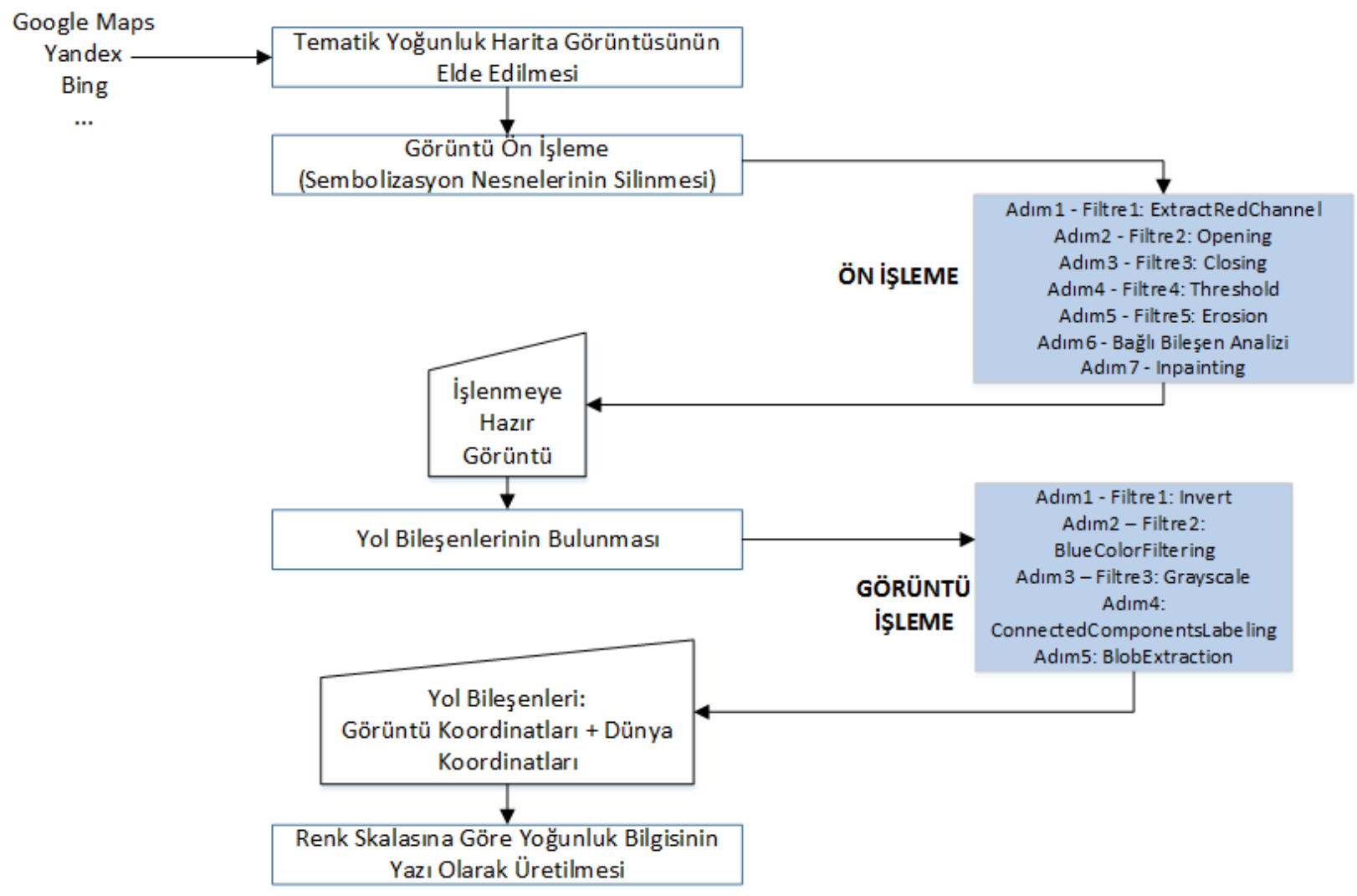

Şekil 7. Akış Diyagramı

\section{Sonuç}

Sunulan yöntem, bir sistemi, tek başına trafik yoğunluk verisi ile besleme yöntemi olarak düşünülmemelidir. Aksine, yoğunluk verisini üreten ya da elde edilen yöntemlere alternatif bir yöntem olarak ele alınmalıdır. Yöntemin, literatürde yer alan diğer yöntemlerle karşılaştırmalı sonuçları aşağıda farklı başlıklar altında açıklanmıştır.

\subsection{Veri Kaynağı ve Yöntem Alt Yapısı Açısından Karşılaștırma}

Yoğunluk verilerinin elde edilmesi için şüphesiz ki 
en iyi yöntem, karayollarını görüntüleyen kameralar ile elde edilen görüntülerin işlenmesidir. Ancak bu yöntem şehir içerisinde birçok farklı konuma bir donanım birimi yerleştirmesini gerektirir. $\mathrm{Bu}$ da maliyetli bir süreçtir. Yeni nesil uygulamalardan birisi olan Yandex uygulaması ise yoğunluk verilerini temel olarak kullanıcı anlık konumlarını elde ederek toplamaktadir. Ancak bu durumda da trafikte yer alan her araç sürücüsünün uygulamayı mobil cihazına kurmuş olması ve uygulama sahibinin konumunu izlemesine izin vermesini gerektirmektedir. Yoğunluk verilerini farklı yöntem ve kaynaklardan elde ederek internet üzerinden kullanıcılara sunan farklı uygulamaların görüntülerinin işlenmesi üzerine çalışan yöntem ise birçok farklı yöntem ve veri kaynağını bir araya getirerek bir sonuç üretmektedir.

\subsection{Farklı Şehir ve Ülkelerde Çalışabilirlik}

Kamera donanımına bağlı olarak çalışan yöntemde, kamera donanımının sistemin çalışacağı şehir içerisine farklı konumlarda kurulması zorunludur. Özellikle de farklı bir ülkede yöntemin çalıştırılması gerekli olduğunda, bu donanım kurulması süreci, daha da maliyetli ve zor bir unsur haline gelecektir. Sosyal medya üzerinden paylaşılan trafik verilerinin işlenmesi ile trafik yoğunluk bilgilerinin üretilmesi yönteminde ise her sosyal medya hesabına yönelik olarak sistemin yeniden çalıştırılması ve yorum özelinde oluşan hataların giderilmesi gerekli olacaktır. Ayrıca farklı ülkelerde çalışabilirlik için sistemin semantik alt yapısının o ülkeye özgü dile uyarlanması gerekli olacaktır. Ancak dünya genelinde yaygın olarak kullanılan yoğunluk haritalarının görüntülerinin işlenmesinde, herhangi ek bir işleme gerek kalmaksızın yöntem olduğu haliyle çalıştırılabilecektir.

Pilot olarak İstanbul bölgesinde Google Maps uygulamasından elde edilen görüntüler ile elde edilen uygulamada yer alan metot, diğer uygulamalar ile entegre de çalışabilmesi için o uygulamalara ilişkin renk skalasını baz alacak şekilde geliştirmeler yapılmalıdır.

Haritada yer alan sembolizasyon nesnelerinin oluşturduğu problemin giderilmesi için bu nesnelerin harita görüntüsü içerisinde tespit edilerek bir ön işlemeden geçirilmesi ve görüntü içerisinden kaldırılması ile algoritmanın doğruluğu artır1labilecektir.

\section{Kaynaklar}

[1]http://www.ibm.com/smarterplanet/tr/tr/traffic_c 2017. ongestion/visions/?re $=\mathrm{sph}$, Son Erişim Tarihi: 10 Mayıs 2016.

[2] https://itea3.org/project/insist.html, Son Erişim Tarihi: $25 \quad$ Mayis 2016.

[3] Bajcsy R, Tavakoli M. Computer recognition of roads from satellite pictures. IEEE Transactions on Systems, Man, and Cybernetics 6 623-637; 1976.

[4] Laptev I, Mayer H, Lindeberg T, Eckstein W, Steger C, Baumgartner A. Automatic extraction of roads from aerial images based on scale space and snakes. Machine Vision and Applications 12 23-31; 2000.

[5] Mena JB, Malpica JA. An automatic method for road extraction in rural and semi-urban areas starting from high resolution satellite imagery. Pattern Recognition Letters 26 1201-1220; 2005.

[6] Geman D, Geman D, Jedynak B, Jedynak B, Syntim $P$. An active testing model for tracking roads in satellite images. IEEE Transactions on Pattern Analysis and Machine Intelligence 18 1-14; 1995.

[7] Hu J, Razdan A, Femiani JC, Cui M, Wonka P. Road Network Extraction and Intersection Detection From Aerial Images by Tracking Road Footprints. IEEE Transactions on Geoscience and Remote Sensing 45 4144-4157; 2007.

[8] Boggess JE. Identification of roads in satellite imagery using artificial neural networks: A contextual approach. Technical report, Mississippi State University; 1993.

[9] Bhattacharya U, Parui SK: An improved backpropagation neural network for detection of road-like features in satellite imagery. International Journal of Remote Sensing 18 3379-3394; 1997.

[10] Mokhtarzade M, Zoej MJV. Road detection from high-resolution satellite images using artificial neural networks. International Journal of Applied Earth Observation and Geoinformation 9 32-40; 2007.

[11] Dollar P, Tu Z, Belongie S. Supervised learning of edges and object boundaries. In: CVPR '06: Proceedings of the 2006 IEEE Computer Society Conference on Computer Vision and Pattern Recognition. 1964-1971; 2006.

[12] Peng T, Jermyn I, Prinet V, Zerubia J: An extended phase field higher-order active contour model for networks and its application to road network extraction from vhr satellite images. In: ECCV08. 509-520; 2008.

[13] https://www.openstreetmap.org/ Son Erişm Tarihi: 17 Haziran 2017.

[14]http://www.movable-

type.co.uk/scripts/latlong.html, Son Erişm Tarihi: 13 Temmuz 2016.

[15]http://homepages.inf.ed.ac.uk/rbf/HIPR2/hough .htm, Son Erişm Tarihi: 17 Haziran 